\title{
Disordered prolactin secretion in the obese child and adolescent
}

\author{
E CACCIARI, E FREJAVILlE, A BALSAMO, A CICOGNANI, P PIRAZZOLI, F BERNARDI, \\ AND F ZAPPULLA
}

2nd Paediatric Clinic, University of Bologna, Italy

SUMmaRY Thirty-eight obese (13 prepubertal, 25 pubertal) boys, and 17 obese ( 6 prepubertal, 11 pubertal) girls underwent a thyroid-releasing hormone test with assay of prolactin. Obese prepubertal boys had prolactin levels that were significantly below those of the control group both under basal conditions and after stimulus. In the obese pubertal boys the difference was significant only after stimulus. The pituitary prolactin reserve in obese pubertal girls was lower than that of the control group. We conclude that in children and adolescents obesity may induce a hypothalamopituitary disorder that affects prolactin secretion.

In the obese child there is an alteration in the hypothalamo-pituitary function which is demonstrated by the decreased release of growth hormone after insulin stimulus. ${ }^{1}$ Furthermore in the obese adult there is a disorder of prolactin secretion. ${ }^{2}$

We have studied prolactin secretion in the obese child and adolescent.

\section{Patients and methods}

\section{Patients.}

\section{Boys}

13 obese prepubertal boys whose mean chronological age was 10 years (range 7 years 1 month to 13 years), mean bone age 10 years 4 months (range $6 \frac{1}{2}$ to $13 \frac{3}{4}$ years); their mean weight excess was $46 \%$ (range $21 \cdot 7$ to $65 \%$ ).

25 obese pubertal boys (Tanner's stage II-III) ${ }^{3}$ whose mean chronological age was 12 years (range 10 years 5 months to 14 years 10 months), mean bone age 12 years 5 months (range 10 to 14 years); their mean weight excess was $45 \cdot 2 \%$ (range 20 to $75 \%$ ).

\section{Girls}

Six obese prepubertal girls whose mean chronological age was 9 years 4 months (range 6 years 4 months to 12 years), mean bone age 10 years 8 months (range 8 to $12 \frac{1}{2}$ years); their mean weight excess was $52 \%$ (range 38 to $70 \%$ ).

11 obese pubertal girls (Tanner's stage II-III) ${ }^{3}$ whose mean chronological age was 11 years 8 months (range 10 years 2 months to 15 years 4 months), mean bone age 13 years 4 months (range 11 to 15 years 3 months); their mean weight excess was $42 \cdot 8 \%$ (range $21 \cdot 8$ to $67 \cdot 5 \%$ ).

\section{Controls.}

The following groups of short-normal subjects were studied.

\section{Boys}

17 prepubertal boys whose mean chronological age was 10 years (range 7 to 13 years), and mean bone age was $8 \frac{3}{4}$ years (range $6 \frac{1}{2}$ to $11 \frac{1}{2}$ years).

18 pubertal boys (Tanner's stage II-III) ${ }^{3}$ whose mean chronological age was 13 years 2 months (range 9 years 7 months to 15 years 4 months), and mean bone age was 11 years 8 months (range $8 \frac{1}{2}$ to 14 years).

\section{Girls}

Seven prepubertal girls whose mean chronological age was 9 years 4 months (range 7 to $12 \frac{3}{4}$ years) and mean bone age was $8 \frac{1}{4}$ years (range 6 years 10 months to 11 years).

Five pubertal girls (Tanner's stage II-III) ${ }^{3}$ whose mean chronological age was $12 \frac{1}{4}$ years (range 10 to 13 years 9 months) and mean bone age was 11 years 3 months (range 8 to 15 years 3 months).

All the subjects, with their parents' consent, were submitted to a thyroid releasing hormone (TRH) test for the evaluation of the prolactin and thyroidstimulating hormone (TSH) release. The TRH test was performed in the following way: in the morning, after an overnight fast, a dose of $100 \mu \mathrm{g}$ TRH was injected intravenously between 0800 and 0900 hours. Blood samples were collected for the assay of TSH and prolactin immediately before the injection and then 20,40 , and 60 minutes after it. 
The pituitary reserve of prolactin and TSH was evaluated by calculating the values of the maximum peak, the maximum increase, and the area of the curve. ${ }^{4}$ Bone age was calculated according to the method of Greulich and Pyle. ${ }^{5}$ Prolactin was assayed by means of the CEA-IRE-Sorin kit which gives the results in $\mu \mathrm{U}$. The kit standard was expressed in international units equal to the standard MRC $71 / 282$. The difference between this standard and the $\mathrm{N} 1 \mathrm{H}$ type No 1 is that $40 \mu \mathrm{U}$ MRC $=1 \mathrm{ng} \mathrm{N} 1 \mathrm{H}$ No 1.

TSH was assayed according to the method of Odell et al., ${ }^{6}$ using the standard MRC 68/38.
We made sure that the values were arranged (with an acceptable approximation) according to the normal-logarithmic distribution; therefore the statistical analysis was carried out on decimal logarithm.

The statistical analysis of the results was carried out by means of the Student's $t$ test and by calculating the $r$ correlation coefficient.

\section{Results}

Tables 1 and 2, and the Figure, give the results from the prepubertal and pubertal boys and girls.

Table 1 Mean bone age and mean chronological age $\pm S E M, T S H(\mu U / m l)$, and prolactin $(\mu U / m l)$ mean values $\pm S E M$ and respective $\log _{10} \pm S D$ before and after TRH administration in obese and normal, prepubertal and pubertal boys

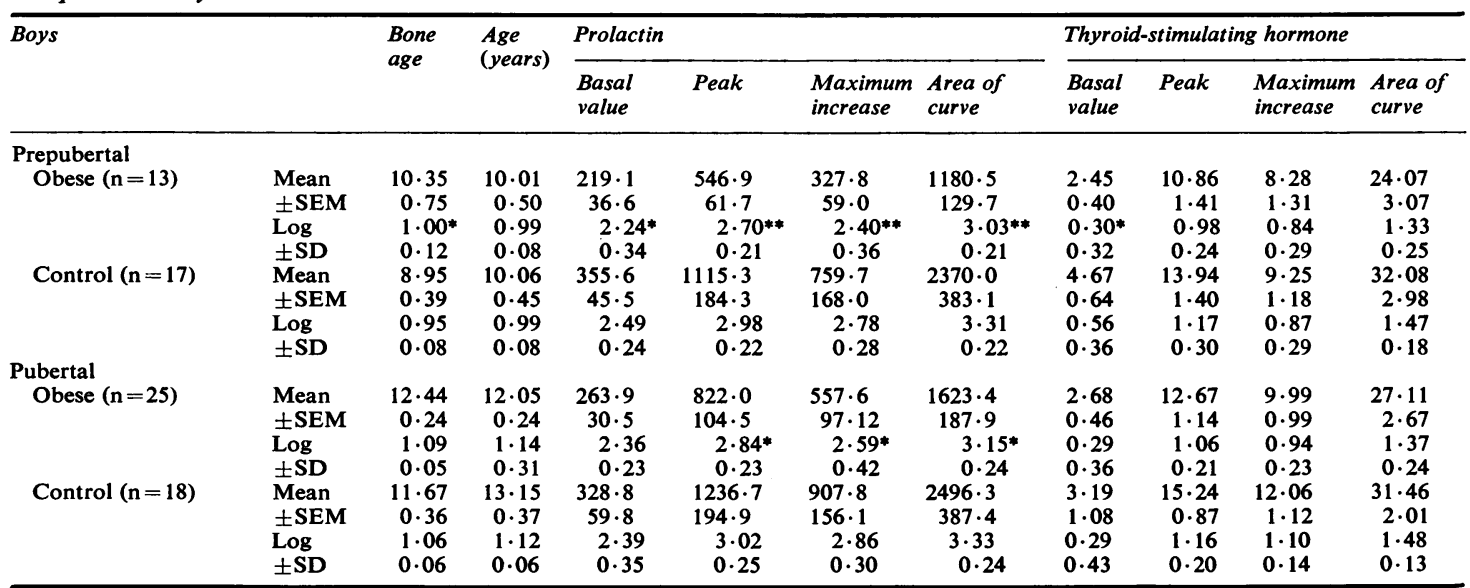

${ }^{*} \mathrm{P}<0.05$ for the difference with control group, ${ }^{* *} \mathrm{P}<0.01$ for the difference with control group.

Table 2 Mean bone age and mean chronological age $\pm S E M, T S H(\mu U / \mathrm{ml})$, and prolactin $(\mu U / \mathrm{ml}) \mathrm{mean}$ values $\pm S E M$ and respective $\log _{10} \pm S D$ before and after TRH administration in obese and normal, prepubertai and pubertal girls

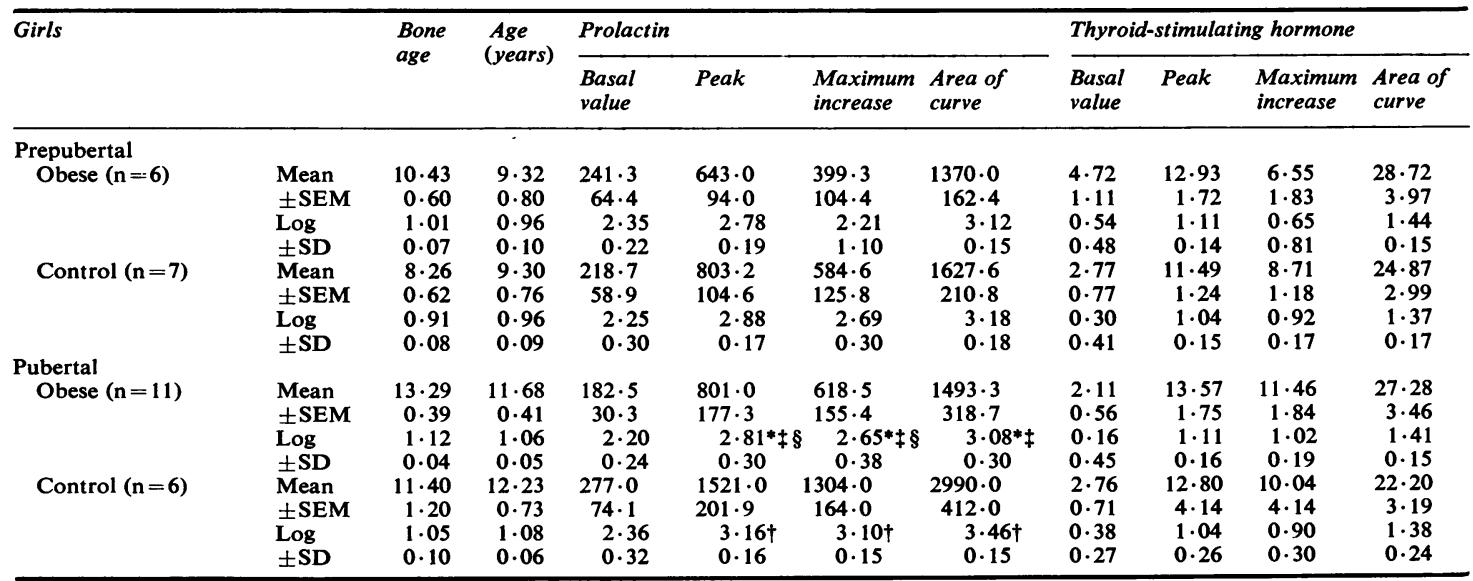

*P<0.05 for the difference with control group, $+\mathbf{P}<0.05$ for the difference with prepubertal control group, $¥ \mathbf{P}<0.05$ for the correlation $(+)$ with chronological age, $\$ \mathrm{P}<0.05$ for the correlation $(-)$ with weight excess. 

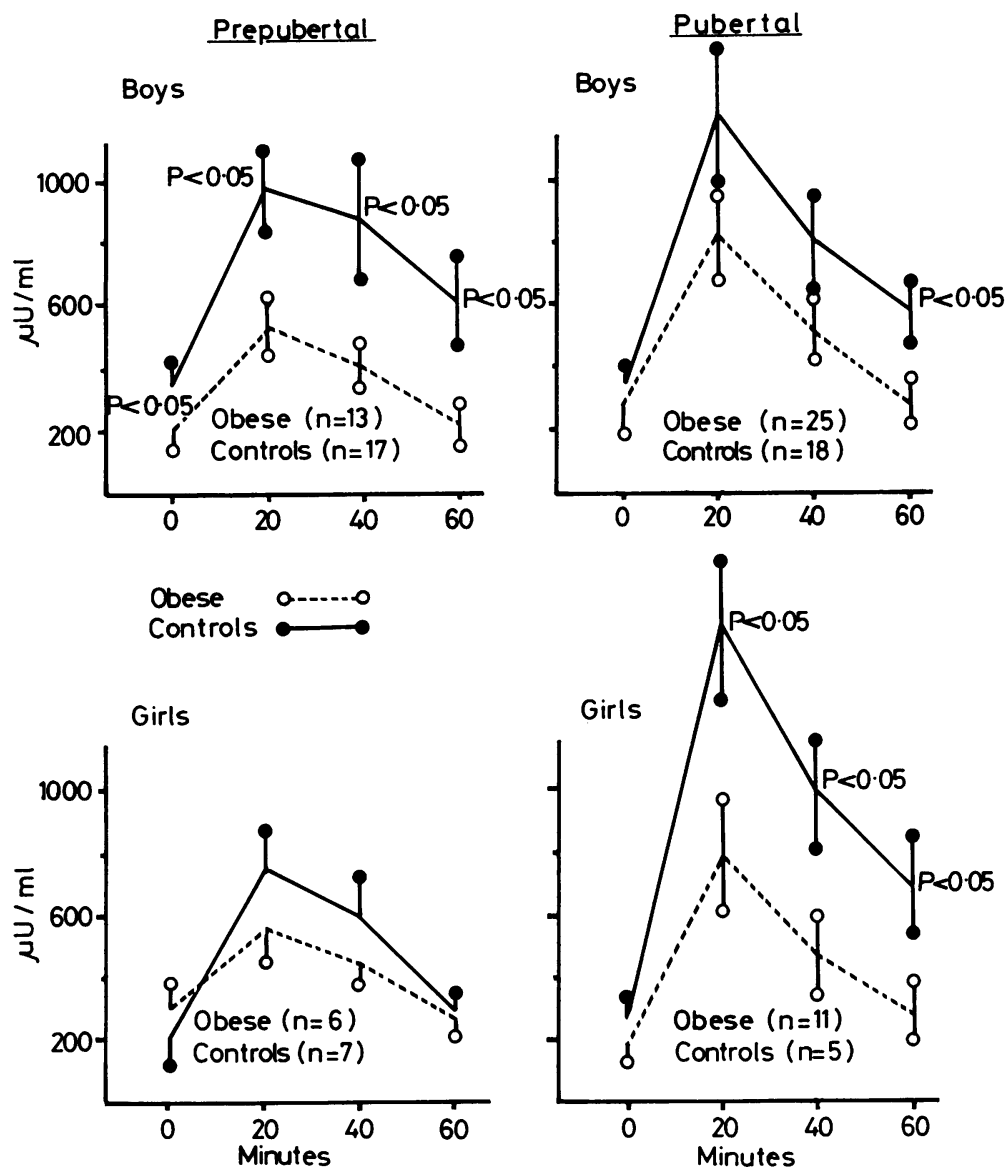

Figure Prolactin $(\mu U / m l)$ mean values $\pm S E M$ before and after TRH test $(100 \mu \mathrm{g}$ intravenously) in normal and obese, prepubertal and pubertal boys and girls

In the obese prepubertal boys the basal values $(P<0.05)$, the peak, the increase, and the area $(P<0.01)$ of the curve of the prolactin, and the basal value of the TSH $(\mathrm{P}<0.05)$ were significantly below those of the control boys.

In the pubertal boys prolactin from the obese subjects was significantly lower $(P<0.05)$ than that from the control group boys in peak, maximum increase, and area of the curve.

Neither in the prepubertal nor pubertal children was there any correlation between the prolactin values (basal, peak, increase, and area) and bone age, chronological age, or weight excess. There were no differences between the pubertal and prepubertal boys, whether obese or of normal weight.

There was no significant difference in hormone values between the prepubertal obese girls and the control prepubertal girls, although the bone age of the control subjects was lower $(P<0.05)$ than that of the obese group.
The pubertal obese girls gave prolactin values (peak, increase, and area) that were lower $(\mathrm{P}<0.05)$ than those of the control group. There was a negative correlation $(P<0 \cdot 05)$ between weight excess and prolactin peak and increase. There was a positive correlation in the obese pubertal girls between chronological age and prolactin peak, increase, and area $(P<0 \cdot 05)$.

There was no significant difference between pubertal and prepubertal obese girls. The normal prepubertal girls had prolactin values (peak, increase, and area) that were lower $(P<0.05)$ than those from the pubertal girls.

There were no differences between male and female prepubertal and pubertal, obese and normal.

\section{Discussion}

Our results show that in the obese adolescent and child, just as in the obese adult, ${ }^{2}$ there is a 
hypothalamo-pituitary disorder which affects prolactin release. Although the number of children we studied was small, we consider that the hypothalamopituitary disorder appears to express itself differently in the two sexes, despite the fact that in both sexes there is the same tendency towards lower prolactin secretion.

In the male the alteration is most clearly evident during the prepubertal stage when the defect in the production of prolactin affects both the pituitary reserve and its tonic secretion. Indeed, before puberty the basal values, peak values, increase, and area of the curve values are all lower than those of the control groups (Table 1 and Figure).

During the pubertal stages, even though all the values from the obese children are lower than those of the normal children, the difference is significant only for the pituitary reserve (peak, maximum increase, and area of the curve). We do not believe that this depends on the different chronological age of the obese children compared with the control group, since age does not have a great influence on the prolactin secretion in the male, ${ }^{78}$ and we found similar values for prepubertal and pubertal children, and no correlation between chronological age and prolactin.

In the female, obesity appears to express its effect particularly during puberty. In the prepubertal girls we did not find any differences related to obesity, whereas in the pubertal stages the pituitary reserve of prolactin in the obese girls is clearly lower than that of the control group, as is demonstrated by the lower values of the peak, the increase, and the area (Table 2 and Figure).

The effect of obesity in the female is particularly obvious during the physiological increase in prolactin secretion which characterises the years of sexual maturation. ${ }^{89}$ This increase in prolactin secretion which is linked to age in the female, is shown in our results by the higher pituitary reserve of the normal pubertal girls when compared with the prepubertal ones $(P<0.05)$, and by the correlation between chronological age and pituitary reserve in obese pubertal girls. We must stress that the lack of difference between the prepubertal control and obese girls might have been due to the small number of children studied, and to the greater $(\mathrm{P}<0.05)$ bone age of the obese girls compared with control group.

Both in the normal and obese children we found no difference between males and females of the same age and the same pubertal stage. This confirms the data provided by others ${ }^{10}$ for normal subjects.

We suggest that the abnormal behaviour of prolactin in the obese child and adolescent can be attributed to anomalous nutritional habits which influence the dopaminergic mechanism of the central nervous system. We assume that a genetic factor is concerned. In support of this suggestion is the fact that the genetically-obese mouse has very low prolactin values before becoming obese. ${ }^{11}$

The obese adult ${ }^{12}$ and child ${ }^{13}$ have decreased testosterone release. Rubin et al. ${ }^{14}$ suggest that prolactin may stimulate the Leydig cells. Therefore the decreased release of prolactin may be responsible for the depression of endocrine-gonadal function in obese people.

\section{References}

1 El-Khodary A Z, Ball M F, Krop T M, Canary J J. Inappropriate growth hormone response to hyperglycemia in obesity irrespective of bodyweight (abstract). Clin Res 1969; 17: 545.

2 Kopelman P G, White N, Pilkington T R E, Jeffcoate S L. Impaired hypothalamic control of prolactin secretion in massive obesity. Lancet 1979; i: 747-9.

3 Tanner J M. Growth at adolescence, second edition. Oxford: Blackwell, 1962.

4 Cacciari E, Cicognani A, Pirazzoli P, et al. Relationships among the secretion of $\mathrm{ACTH}, \mathrm{GH}$, and cortisol during the insulin-induced hypoglycemia test in the normal and obese child. J Clin Endocrinol Metab 1975; 40: 802-6.

${ }^{5}$ Greulich W W, Pyle S I. Radiographic atlas of skeletal development of the hand and the wrist. Stanford, Connecticut: Stanford University Press, 1959.

6 Odell W D, Wilher J F, Paul W E. Radioimmunoassay of thyrotrophin in human serum. J Clin Endocrinol Metab 1965; 25: 1179-88.

7 Ehara Y, Yen S S C, Siler T M. Serum prolactin levels during puberty. Am J Obstet Gynecol 1975; 21 : 995-7.

8 Apter D, Pakarinen A, Vihko R. Serum prolactin, FSH, and LH during puberty in girls and boys. Acta Paediatr Scand 1978; 67: 417-23.

9 Sizonenko P C. Endocrinology in pre-adolescents and adolescents. I. Hormonal changes during normal puberty. Am J Dis Child 1978; 132: 704-12.

10 Aubert M L, Grumbach M M, Kaplan S L. Heterologous radioimmunoassay for plasma human prolactin (hPRL); values in normal subjects, puberty, pregnancy, and in pituitary disorders. Acta Endocrinol 1974; 77 : 460-76.

11 Larson B A, Sinha Y N, Vanderlaan W P. Serum growth hormone and prolactin during and after the development of the obese-hyperglycemic syndrome in mice. Endocrinology 1976; 98: 139-45.

12 Amatruda J M, Hochstein M, Hsu T H, Lockwood D H. Testosterone deficiency of morbid obesity (abstract). Clin Res 1975; 23: 571 .

13 Cacciari E, Cicognani A, Pirazzoli P, et al. Effects of obesity on the hypothalamo-pituitary-gonadal function in childhood. Acta Paediatr Scand 1977; 66: 345-8.

14 Rubin R T, Poland R E, Tower B B. Prolactin-related testosterone secretion in normal adult men. $J$ Clin Endocrinol Metab 1976; 42: 112-6.

Correspondence to Professor E Cacciari, Clinica Pediatrica dell' Università, Via Massarenti 11, 40138 Bologna, Italy.

Received 5 December 1979 